Journal of Applied Veterinary Sciences, 5 (4): 55 - 60 (2020).

ISSN: Online: 2090-3308, Print: 1687-4072

Journal homepage : https://javs.journals.ekb.eg

\title{
Preliminary Studies on The Virus Causing Outbreak of Duckling Short Beak and Dwarfism Syndrome (SBDS) in Egypt
}

\author{
Amani Ali Saleh* and Mohamed Hassan Khodier \\ Veterinary Serum and Vaccine Research Institute (VSVRI), Agricultural Research Center (ARC), Abbasia, \\ Cairo, Egypt. \\ "Corresponding Author, Amani Ali Saleh, E-mail: Dr.amani-ali@ hotmail.com
}

\begin{abstract}
Many Mule, Muscovy, and Bikini duck flocks in different duck-producing regions in Egypt have shown signs of a new disease designated "short beak and dwarfism syndrome" (SBDS) since 2015. The ducks with SBDS showed strong growth retardation with beak atrophy, enteritis, and paralysis. Although the mortality rate was $2 \%-8 \%$ in affected flocks, the morbidity rate was $20 \%-50 \%$ and even $80 \%$ in some regions. The disease is characterized by dyspraxia, weight loss, a protruding tongue, and high morbidity and low mortality rates. To characterize the etiological agent, a virus was isolated from the allantoic fluid following serial passage in embryonated duck eggs. This virus causes a cytopathic effect in duck embryo fibroblast (DEF) cells. Using enzyme-linked immunosorbent assay (ELISA), the isolate was positive for the antigen of goose parvovirus (GPV). The bovine sperm agglutination test indicated that the virus was most closely related to GPV strain. Together, these data indicated that the isolated virus from mule ducks with SBDS disease is a GPV-related parvovirus causing and that it is divergent from classical GPV isolates.
\end{abstract}

Keywords: Bikini duck, Dwarfism, ELISA, SBDS, Syndrome.

\section{Original Article: \\ DOI:https://dx.doi.org/10.21608/ja vs.2020.118004}

Received :17 Aug., 2020.

Accepted :30 Sept., 2020.

Published in October, 2020.

This is an open access article under the term of the Creative Commons Attribution 4.0 (CCBY) International License . To view a copy of this license, visit:

http://creativecommons.org/licenses/by/4.0/

\section{INTRODUCTION}

Waterfowl parvovirus infections are generally divided into goose parvovirus (GPV) and Muscovy duck parvovirus (MDPV). GPV infects both goslings and Muscovy ducks, causing Derzsy's disease (Derzsy et al., 1970) while MDPV infects Muscovy ducklings, causing a disease known as "three-week disease". Both types of infection are fatal to waterfowls.

Derzsy's disease or gosling plague was first reported in 1969 due to high morbidity and mortality in young Muscovy ducklings and goslings (Dressy, 1967; Jansson et al., 2007). Short beak and dwarfism syndrome (SBDS) was first reported in France in the early 1970s in mule duck flocks (mule duck, a sterile intergeneric hybrid produced by crossing Peking and Muscovy duck). The diseased flocks showed retarded growth with short beaks (Palya et al., 2009). In 2017, SBDS was reported in Egypt in Gharbya and Sharqya governments. The etiological agent of SBDS is a novel goose parvovirus (NGPV), which shared the highest homology with goose parvovirus (GPV) and was regarded as a variant of GPV (Palya et al., 2009; Chen et al., 2015). NGPV was not a lethal etiological agent in ducks, but farmers suffered from great economic losses due to reduced sales of NGPV-infected ducks.

NGPV infects 1-day-old Cherry ducks and Mule ducks and demonstrates a high rate of infection with low mortality. Most ducks develop asymptomatic infections, but those with significant clinical symptoms showed growth retardation, atrophied beaks, a protruding tongue outside of the beak, swelling and hemorrhage of the thymus, and fractured feathers and legs (Palya et al., 2009; Chen et al., 2015 and Chen et al., 2016).

Nnovel goose parvovirus (NGPV), a waterfowl parvovirus, along with GPV and MDPV, belongs to Anseriform depend on parvovirus but is distinguished from other depend on viruses by its ability to replicate autonomously in vitro without helper-viruses (Kisary, 1979, Brown et al., 1995). In the family Parvoviridae, the waterfowl parvoviruses are small non-enveloped viruses with a linear, singlestranded DNA genome of approximately $5.1 \mathrm{~kb}$ in length (Zadori et al., 1994, Woz'niakowski et al., 2009; Ji et al., 2010 and Wang et al., 2016). 
The full-length genome contains two open reading frames (ORFs): the left ORF codes for the nonstructural proteins NS1 and NS2 (Smith et al., 1999) and the right ORF codes for the structural proteins VP1, VP2 and VP3 (Zádori et al., 1995). Additionally, there are two inverted terminal repeats (ITRs) at both ends of the genome (Zádori et al., 1995; Poonia et al., 2006).In general, parvoviruses agglutinate erythrocytes , but the goose parvovirus (GPV) is an exception. The GPV cannot agglutinate red blood cells but agglutinates bovine sperm (Brown et al., 1995).

Based on the serological investigation and phylogenetic analysis, it was suggested that the syndrome was caused by a distinct GPV that was very difficult to isolate from clinical samples. Palya $\boldsymbol{e t}$ al. (2009) first isolated this distinct GPV and successfully reproduced this disease by experimental infection. In 1989, a similar disease designated" duckling atrophic beak with protruding tongue and stunted growth disease" was reported with significantly higher morbidity and mortality than that reported in France (Palya et al., 2009).

As a waterfowl parvovirus, NGPV can propagate autonomously. In previous reports, the viruses isolated by Palya et al. (2009) were adopted in Muscovy duck eggs after being blindly propagated for one or two passages. The other strains were adapted in ducks after three- or four-blind propagations and could only cause a cytopathic effect (CPE) in duck embryo fibroblasts (DEFs) (Brown et al., 1995, Chen et al., 2015). It was collectively demonstrated that NGPV could replicate in duck eggs and DEFs, but the details about the adaption process and growth curve of NGPV were not reported. During propagation, waterfowl parvovirus shows both autonomous and dependent virus parvoviruses (Palya et al., 2009; Ji et al., 2010). Certain parvoviruses such as $\mathrm{H}-1$ can cause cytopathic effects (CPE) and induce apoptosis in infected cells through the process of replication (Poonia et al., 2006). Still, it is unclear whether NGPV has apoptosis effect.

In this study, Mulard (mule) duckling flocks in different duck-producing areas of Egypt develop SBDS disease was reported. SBDS disease mostly affects young Mulard, Muscovy and Bikini ducklings, characterized by a notably atrophic beak and protruded swollen tongue, stunted growth, fractured feathers and legs, high morbidity, and low mortality. No diagnostic histopathologic lesions other than enteritis were observed. Resistance against the disease increased with age. This disease was not found to be present in adult ducks. Due to the striking loss of weight and size caused by SBDS, the disease causes much economic loss to the Egyptian duck industry. The NGPV local strain was isolated, and its growth characteristics were investigated, laying a foundation for further vaccine and viral molecular research.

\section{Sample collection \\ To diagnose this epidemic disease, liver,} spleen, and intestine samples from infected birds identified as NGPV positive infection were collected from five different duck farms and used for isolation of the virus. The samples were homogenized in phosphate-buffered saline (PBS, pH 7.2) and centrifuged at $6000 \mathrm{rpm}$ for $15 \mathrm{~min}$. The supernatant was filtered through a $0.22-\mu \mathrm{m}$ filter then the filtered supernatant was stored at $-80^{\circ} \mathrm{C}$.

\section{Virus isolation and adaption in embryonated duck eggs}

Muscovy embryonated duck eggs (9-11-dayold) were inoculated in the allantoic fluid with the filtered supernatant (previously prepared) $(0.2 \mathrm{ml} / \mathrm{egg})$ and the inoculated eggs were checked daily till the death of the embryo for survival. If the embryos survived, allantoic fluid was collected, pooled, and used to inoculate embryonated duck eggs for further passages. If the embryo died within days, the allantoic fluid and internal organs were tested for ELISA's waterfowl parvovirus antigens.

\section{Virus isolation and adaption in duck embryo fibroblast cells (DEFs)}

Duck embryo fibroblasts $\left(\mathrm{DEF}_{\mathrm{s}}\right)$ cells were prepared from 11-day-old Muscovy duck embryos as described previously (Shahsavandi $\boldsymbol{e t}$ al., 2013). The DEFs were inoculated with the filtered supernatant (previously prepared) at a 1:10 dilution and incubated at $37^{\circ} \mathrm{C}$ in $5 \% \mathrm{CO}_{2}$. At the same time, the DEFs in the control group were inoculated with PBS. The infected cells underwent three freeze-thaw cycles seven days after inoculation prior to harvest and storage at $-80^{\circ} \mathrm{C}$ for the next infection and detecting CPE. The virus was then serially passaged five times in DEFs. After the virus adaptation to the cells, the CPE was observed daily for up to 7 days. An apparent cytopathic effect (CPE) was considered positive for virus replication.

\section{Enzyme-Linked Immunosorbent Assay (ELISA KIT)}

Confirmation can be obtained in infected flock tissues and post isolation of the parvovirus in cell cultures or embryonated eggs derived from susceptible Muscovy ducks. The virus's presence can be confirmed by the Geese parvovirus antigen ELISA kit (Shanghai Coon Koon Biotech Co., Ltd. The optical density (OD) values were observed at $450 \mathrm{~nm}$ using an automated enzyme-linked immunosorbent assay (ELISA) plate reader (Thermo, Waltham, MA, USA).

\section{Bovine sperm agglutination test}

GPV can agglutinate bovine sperm, and this feature can be used for virus identification (Yakun and Shangjin, 2015). The virus to be tested is diluted in saline (ratio 1:5) and $0.25 \mathrm{ml}$ was added in a small test 


\section{Amani Ali Saleh and Mohamed Hassan Khodier}

tube. In comparison, in a second tube, $0.25 \mathrm{ml}$ of physiological saline was added as a control tube, then $0.25 \mathrm{ml}$ buffered cattle semen (semen was added to 1 $\mathrm{ml}$ of $2.9 \%$ tri-sodium citrate solution at $42^{\circ} \mathrm{C}$ ) was added to each tube, mixed, and set at room temperature for six $\mathrm{h}$ before observation. Animal Reproduction Research Institute, El-Giza supplied bovine semen.

\section{RESULTS}

\section{Clinical symptoms}

Several cases of a new disease in commercial meat ducks were reported in the Gharbya government (Byrma) and the outbreaks have since spread to several primary duck production regions. The cases were typically characterized clinically by tongue protrusion accompanied by a shortened beak (Fig.1 A and B), with approximately 10 to $30 \%$ morbidity and 2 to $6 \%$ mortality at the end of the growth period. The final beak size was approximately 10 to $30 \%$ of the normal beak of a healthy duckling. Poor beak development resulted in protruded tongues in previously infected ducklings, significantly affecting their ability to move, eat and drink (Fig. $1 \mathrm{C}$ and D). As a result, the diseased ducklings continued to have poor growth and increased mortality.
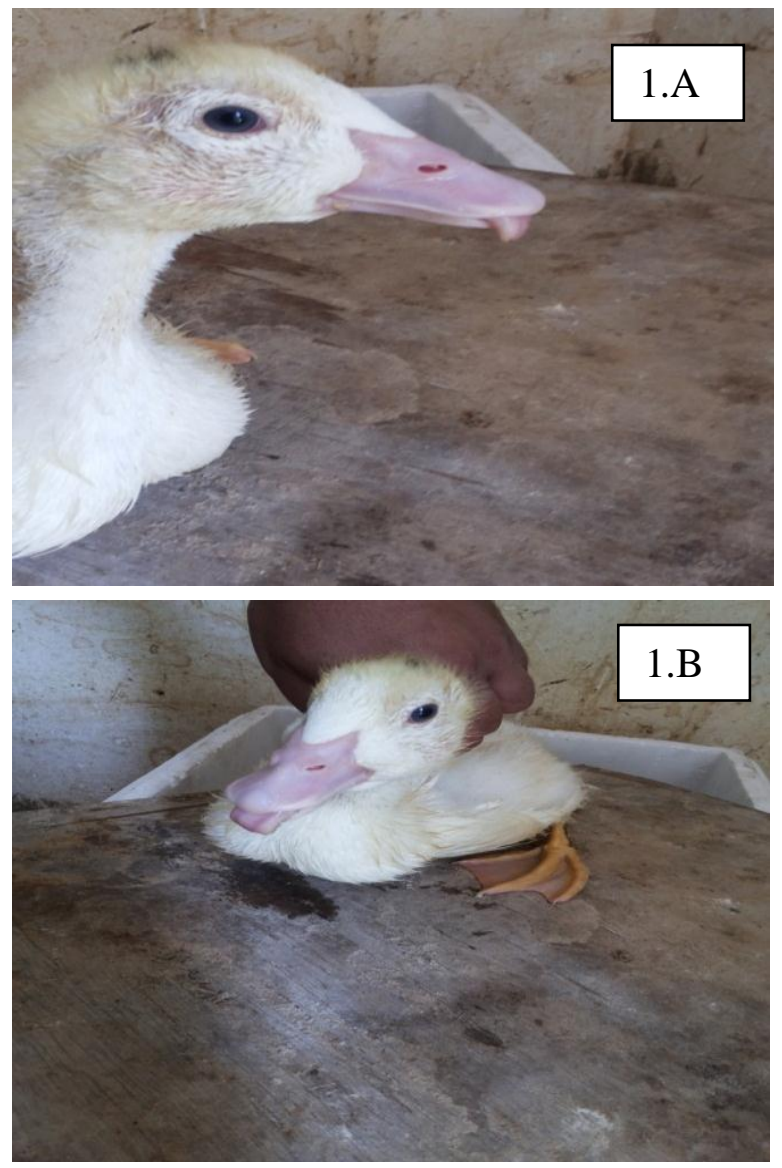

Fig.1: Typical clinical symptoms of SBDS in mule duckling with a short beak, protruding tongue (A\&B). Mule duckling with a movement disorder and broken leg (C\&D).
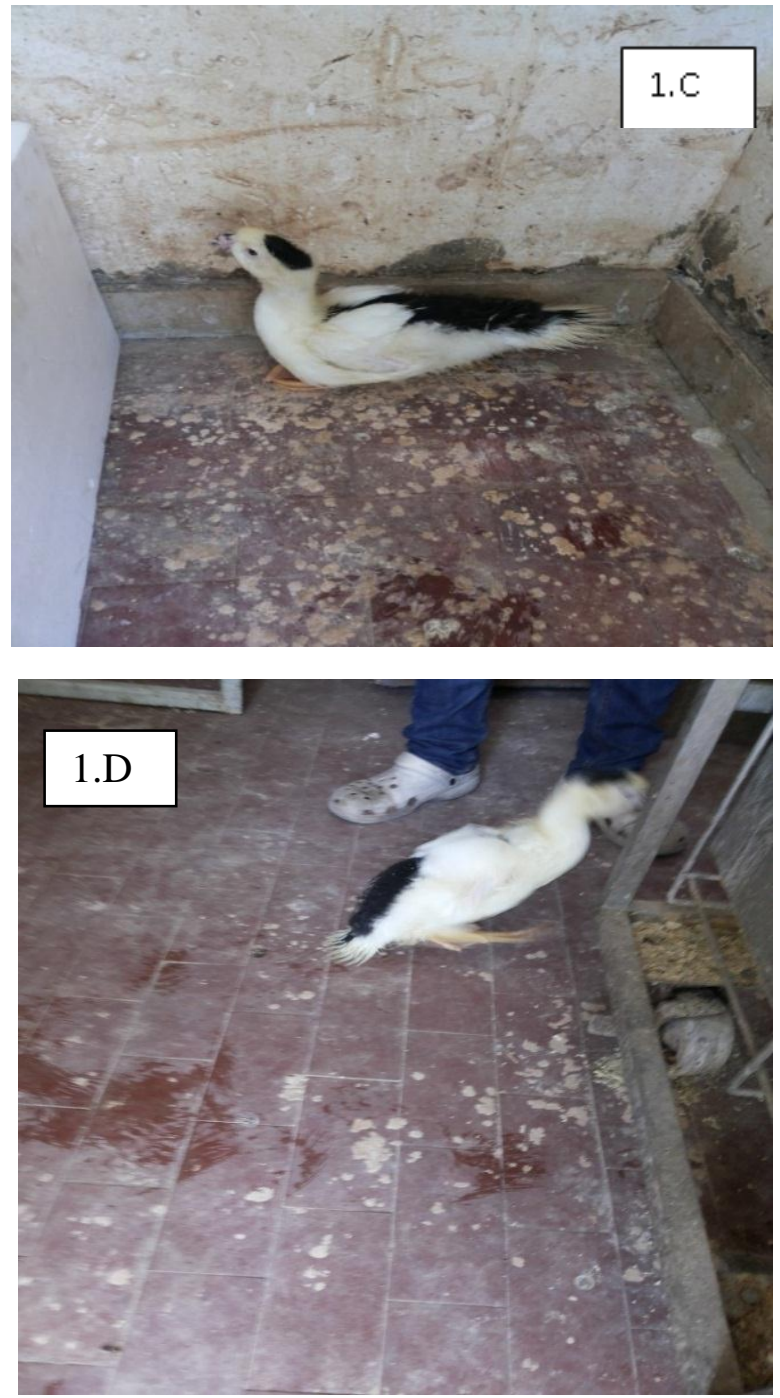

In most cases, the affected ducklings had fragile and easily broken legs, potentially caused by the progressive loss of skeletal muscle mass in the legs. Initial symptoms, including the shortened beak and tongue protrusion, began at the age of one week and peaked at three weeks. Infection rates were much lower in adult ducks above four weeks, and symptoms likely became subclinical. All major duck species (Mulard, Muscovy and Bikini) in this study were found to be susceptible to this new disease, and both males and females were represented among the cases. The morbidity rate was variable among affected duck flocks, ranging from $30 \%$ to $60 \%$. Although the low mortality rate observed for affected farms was not high, ducks' production performance that survived the infection was significantly reduced due to abnormal feathering and growth retardation.

\section{Virus isolation and adaptation in embryonated duck eggs and duck embryo fibroblast cells (DEFs)}

After five blindly passages by the allantoic cavity route through embryonated duck eggs, $60 \%$ of duck embryos died at 72 hours post-inoculation (HPI) with systemic hemorrhage (Fig.2). The isolate generated 
little or no cytopathic effect (CPE) in DEF cell cultures at $96 \mathrm{HPI}$ and on microscopic examination, significant cytopathic effects have occurred 72 HPI after four passages. Infected DEF cells became rounded and shrunken, and by $96-120$ hours, the entire monolayer was destroyed (Fig.3). In each passage, the inoculated cells were harvested, and the virus was detected using ELISA. Overall, the ELISA kit assay demonstrated that the infected cells were positive for GPV.

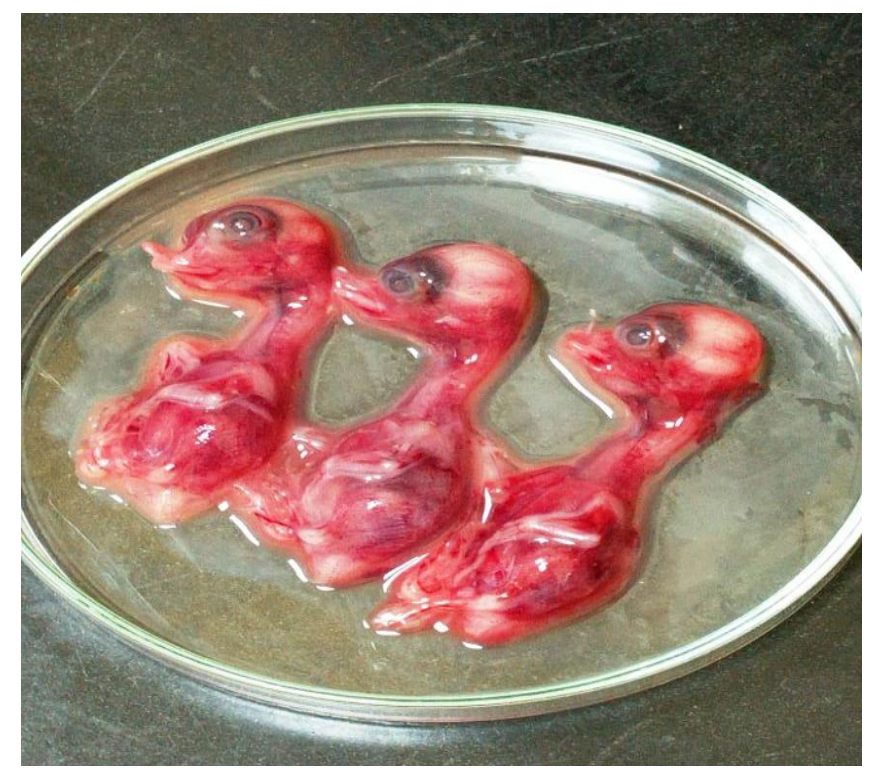

Fig.2: GPV-infected duck embryo showed generalized spots of hemorrhage.

\section{3-Enzyme-Linked Immunosorbent Assay (ELISA KIT)}

The positive and negative cut-off value for optical density (OD) 450 was calculated and the negative cut-off value was rounded off to $\leq 1.0$ to ensure accurate results. Among the tissue samples from infected ducklings, all the five flocks were identified as positive for GPV infection. These positive flocks, whose offspring often manifested SBDS symptoms on the epidemic investigation, were also identified by viral isolation. All the duck egg and cell culture samples of all passages were identified as positive for GPV infection.

\section{Titration of the GPV in embryonated duck eggs and DEFs}

At the fifth passage in duck eggs and seven passages in DEF cell, the allantoic fluids and infected cell cultures of the isolated strain had infectivity titers of $10^{7} \mathrm{EID}_{50} / \mathrm{ml}$ and $10^{6.3} \mathrm{TCID}_{50} / \mathrm{ml}$, respectively, calculated by the Reed-Muench method (Reed and Muench, 1938).

\section{5,Bovine sperm agglutination test}

As the first tube virus agglutinates bovine semen in $2.9 \%$ trisodium citrate solution and the second one does not agglutinate, the virus can be judged as GPV (Fig.4).
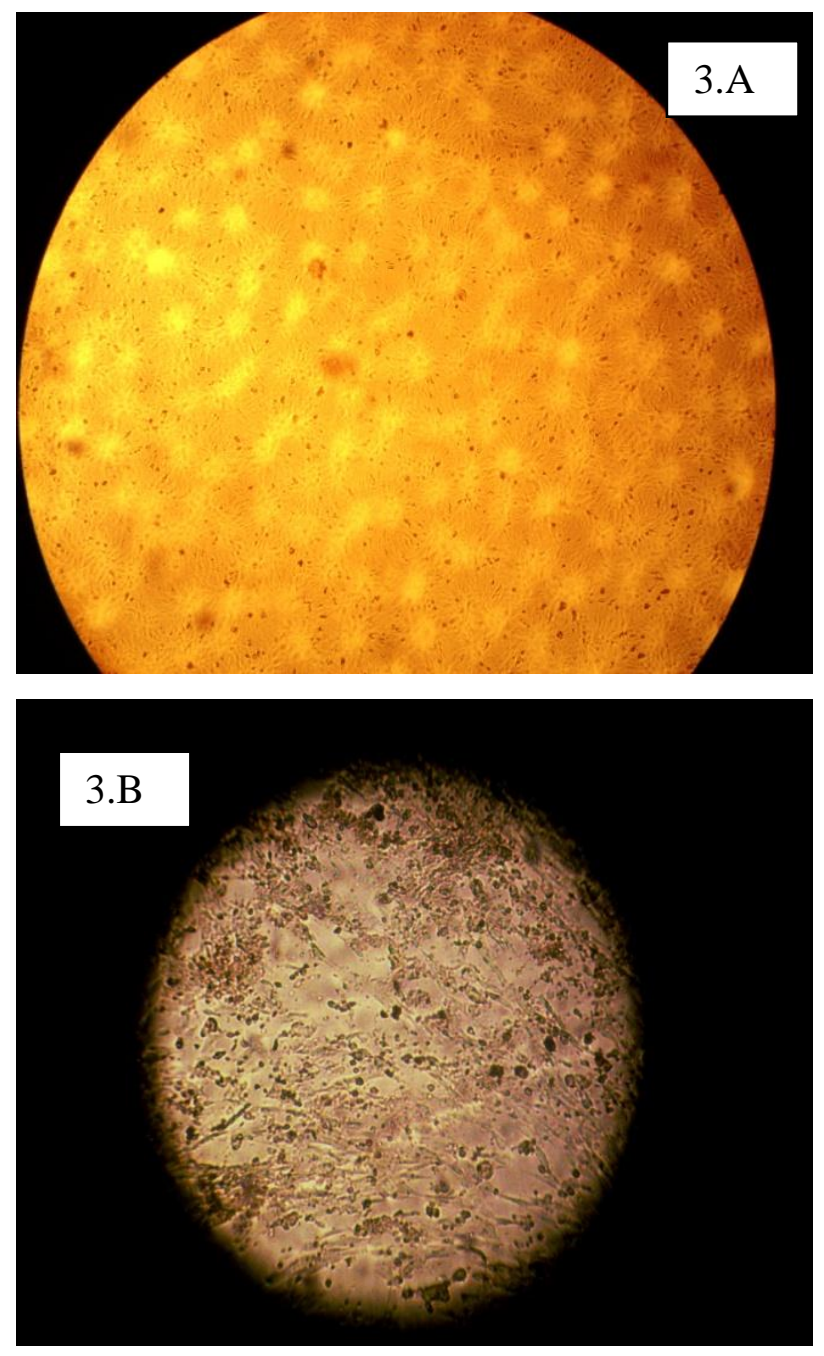

Fig. (3.A) showed normal DEF cells and fig (3.B) showed CPE caused by GPV isolate in infected DEF cells observed at 96 - 120 HPI showing cells rounding and shrunken, and by 96-120 hours, the entire monolayer was destroyed.

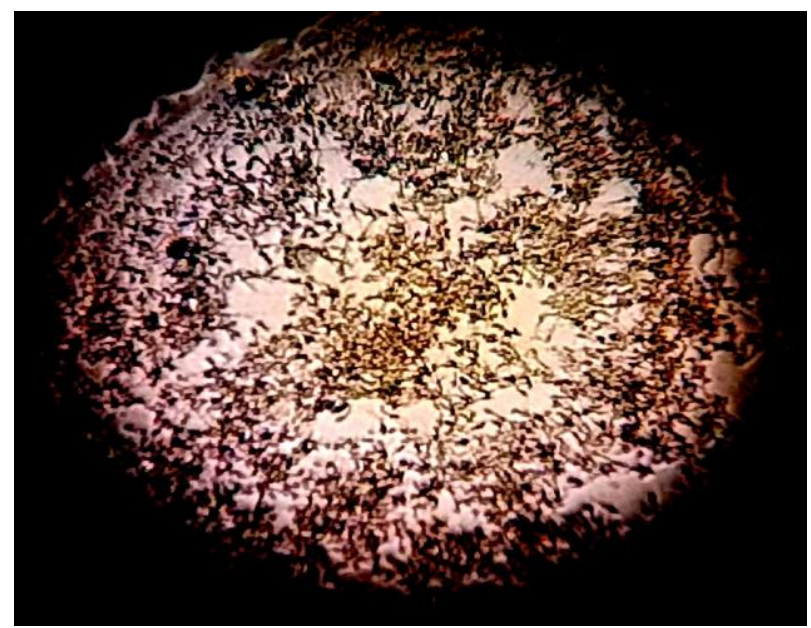

Fig.4: Positive bovine sperm agglutination by GPV isolate 
The pyrazole derivatives with bis-tolyl groups in positions three and five were revealed hydrogen bond acceptor from sidechain between Arg 68 and oxygen of methanone derivative with bond length 2.87 ${ }^{\circ} \mathrm{A}$ and strength (14\%) (Fig. 4). In addition to one arene-cation interaction through the tolyl group at position five and Lys 51 and hydrophobic interaction that arises due to the presence of amantadine and $p$ tolyl moiety.

Furthermore, pyrazole derivatives $6 \mathrm{c}$ that containing phenyl and $p$-chlorophenyl as two aryl derivatives observed binding energy $\mathrm{S}=-18.02$ $\mathrm{kcal} / \mathrm{mol}$ with sidechain hydrogen bond acceptor between Arg 68 and oxygen of carbonyl of the methanone derivative with bond length $2.51{ }^{\circ} \mathrm{A}$ and $(30 \%)$ strength. Besides two arene-cation interaction between Arg 68 with the $p$-chlorophenyl group and Lys 51 with phenyl group at the position three and five in pyrazole core respectively, (Fig.4).

Finally, the pyrazole derivatives hybrid with Amantadine core 6a-c suggested being 3C protease inhibitor and exhibited binding energy higher than the two standard drugs Amantadine $(S=6.15 \mathrm{kcal} / \mathrm{mol})$ and Ribavirin $(\mathrm{S}=10.77 \mathrm{kcal} / \mathrm{mol})$ with different binding mode. All the docked pyrazole derivatives 6a-c showed favorable binding interactions with hydrophobic interaction and energy scores from -15.41 to -20.0 $\mathrm{kcal} / \mathrm{mol}$ in comparison to Amantadine $(\mathrm{S})=-6.15$ $\mathrm{kcal} / \mathrm{mol}$, and Ribavirin $(\mathrm{S})=-10.77 \mathrm{kcal} / \mathrm{mol}$. These highest binding energy and binding interactions suggest that these compounds may act as $3 \mathrm{C}$ protease inhibitors and thus may participate as antiviral drugs.

\section{DISCUSSION}

Mule duck SBDS was reported in France in the 1970s and Hungary in 2009 (Palya et al., 2009). The causative agent was a distinct lineage of goose parvovirus that was very difficult to isolate. A more severe SBDS disease was also reported in Taiwan in 1989, but the causative agent was diagnosed as a coinfection of duck parvovirus and duck viral hepatitis (Chen et al., 2015). However, since 2015, a disease similar to the SBDS was observed in young Chinese Cherry Valley duck flocks (Lu et al., 1993).

In this study, SBDS disease was observed in Mule, Muscovy, and Bikini ducks in Egypt, and this is the first report of SBDS disease existing in both mule ducks and bikini ducks. The viral strain was isolated from ducks with SBDS based on the pathogenic differential diagnosis, disease reproduction. It was found that SBDSV M15 is the causative agent of SBDS disease in China and related to GPV but not MDPV (Chen et al., 2016). In 2015, the NGPV outbreak in a Northern China coastal city resulted from a novel goose parvovirus, which was closely related to the goose parvovirus (GPV) (Lu et al., 1993).

The virus was isolated from the liver and intestinal tract tissues obtained from infected ducks in the current study. After blind-propagation for five passages in vitro (embryonated duck eggs), it was found that the isolate strain infection of duck embryos resulted in death at 72 HPI with systemic hemorrhage (Fig.2). In inoculated DEFs, cytopathic effects were only observed in DEFs after blind-replication for four passages characterized by cells rounding and shrunken. By 96-120 hours, the entire monolayer was destroyed (Fig.3.B), and viral infectivity titers across 5 and 7 passages were $10^{7} \quad \mathrm{EID}_{50} / \mathrm{ml}$ and $10^{6.3} \quad \mathrm{TCID}_{50} / \mathrm{ml}$, respectively. These results appear similar to the previous reports showing that NGPV could be isolated and propagated in duck embryos and DEFs are permissive to NGPV, while GEFs are not (Palya et al., 2009; Chen et al., 2015).

However, NGPV can replicate in duck embryos and cause DEF cell death. It was exciting that NGPV cannot induce apoptosis, which was different from the most parvovirus. Future studies focusing on vaccine development and identifying the mechanisms of NGPV infection are necessary to address this problem going forward (Zhang et al., 2019).

ELISA is a common diagnostic test for detecting various infectious pathogens, and different versions are available, including direct ELISA, antigen capture ELISA, sandwich ELISA, and dipstick ELISA. Recently, Wang et al. (2014) developed a competitive ELISA using a monoclonal antibody to detect GPV virus-like particles and vaccine immunization in goose sera (Wang et al., 2014). The procedural details for ELISA and competitive ELISA are available in published reports (Baxi et al., 2006; Cheng et al., 2009). The obtained results were confirmed by ELISA parvovirus antigen kit and bovine sperm agglutination test for virus identification in all tissue specimens and infected allantoic and tissue cultures fluid.

\section{CONCLUSIONS}

The isolated virus from diseased duck flocks might be a novel Muscovy duck infecting GPV (MDGPV) circulating in Egypt and it appears that variant goose parvoviruses do exist in nature. The high prevalence of GPV and MDPV infection does provide the opportunity for coinfection, the first step in generating recombinant viruses. Genetic data indicate that the MDGPV/ strain has adapted to infect Muscovy ducks, and antigenic variation has resulted in inconsistent responses to traditional GPV vaccines (Wang et al., 2013). Future studies will characterize the isolated GPV sequence, molecular epidemiology of 
virus infections and pathogenesis studies. However, it is important to have a vaccine against duck origin GPV in Egypt.

\section{Declaration of Competing interest}

On behalf of all authors, I hereby declare that no conflict of interest may interfere with the publication of the manuscript.

\section{REFERENCES}

BAXI M, MCRAE D, BAXI S, GREISER-WILKE I, VILCERK S, AMOAKO K, DEREGT D.2006. A one-step multiplex real-time RT-PCR for detection and typing of bovine viral diarrhea viruses. Vet Microbiol. 1-3:37-44.

BROWN KE, GREEN SW, YOUNG NS. 1995. Goose parvovirus-an autonomous member of the dependovirus genus? Virology; 210(2):283-91. doi: 10.1006/viro.1995.1345

CHEN H, DOU Y, TANG Y, ZHANG Z, ZHENG X, NIU $X$, YANG J, YU X, DIAO Y. 2015. Isolation and genomic characterization of a duck-origin GPVrelated parvovirus from Cherry Valley ducklings in China. PLoS One. ;10 (10): e 0140284

CHEN S, WANG S, CHENG X, XIAO S, ZHU X, LIN F, WU N, WANG J, HUANG M, ZHENG M. 2016. Isolation and characterization of a distinct duck-origin goose parvovirus causing an outbreak of duckling short beak and dwarfism syndrome in China. Arch. Virol.; 161(9):1-10

CHENG AC, MINGSHU W, HONGYI $X$, DEKANG $Z$, XINRAN L, HAIJUEN C, RENYONG J, MIAO Y. 2009. Development and application of a reverse transcriptase-polymerase chain reaction detect Chinese isolates of duck hepatitis virus type 1.J Microbiol Methods, 77:332-336.

DERZSY D, DRÉN C, SZEDÖ M, SURJÁN J, TÓTH B, IRÓ E.1970. Viral disease of goslings. 3. Isolation, properties and antigenic pattern of the virus strains. Acta Vet Acad Sci Hung.; 20(4):419-428.

DRESSY D. 1967. A viral disease of goslings. Acta Vet Hung 17:443-448

JANSSON DS, FEINSTEIN R, KARDI V, MATO' T, PALYA V. 2007. Epidemiologic investigation of an outbreak of goose parvovirus infection in Sweden. Avian Dis 51:609-613

JI J, XIE Q, CHEN C, BAI S, ZOU L, ZUO K, CAO Y, XUE C, MA J, BI Y. 201. Molecular detection of Muscovy duck parvovirus by loop-mediated isothermal amplification assay, Poultry Sci. 89:477483

KISARY J. 1979. Interaction in replication between goose parvovirus strain $B$ and duck plague herpesvirus. Arch. Virol.; 59 (1-2):81-88

LU Y, LIN D, LEE Y, LIAO Y, TSAI H. 1993. Infectious bill atrophy syndrome caused by parvovirus in a cooutbreak with duck viral hepatitis in ducklings in Taiwan. Avian Dis 37(2):591-596

PALYA V, ZOLNAI A, BENYEDA Z, KOVA'CS E, KARDI V, MATO' T. 2009. Short beak and dwarfism syndrome of mule duck is caused by a distinct lineage of goose parvovirus, Avian Pathol., 38: $175-180$

POONIA B, DUNN, PA, LU H, JAROSINSKI KW, SCHAT KA. 2006. Isolation and molecular characterization of a new Muscovy duck parvovirus from Muscovy ducks in the USA, Avian Pathol., 35(6):435-441

REED, L.J. AND MUENCH, H. 1938. A simple method for estimating fifty percent endpoints. American Journal of Hygiene, 27, 493-497.

SHAHSAVANDI S, EBRAHIMI MM, MOHAMMADI A, LEBAS NZ. 2013. Impact of chicken-origin cells on adaptation of a low pathogenic influenza virus. Cytotechnology 65:419-424

SMITH D, WARD P, LINDEN R. 1999. Comparative characterization of rep proteins from the helperdependent adeno-associated virus type 2 and the autonomous goose parvovirus. J Virol., 73(4):2930.

WANG, S, CHENG, X. X, CHEN, S Y, ZHU, X. L., CHEN, S L, LING, F. Q, AND LI, Z. L. 2013. Genetic Characterization of a Potentially Novel Goose Parvovirus Circulating in Muscovy duck Flocks in Fujian Province, China. J. Vet. Med. Sci. 75(8): 1127-1130,

WANG Q, JU H, LI Y. 2014. Development and evaluation of a competitive ELISA using a monoclonal antibody for antibody detection after goose parvovirus viruslike particles (VLPs) and vaccine immunization in goose sera. J Virol Methods, 209:69-75.

WANG S, CHENG XX, CHEN SY, LIN FQ, CHEN SL, ZHU XL, WANG JX, HUANG MQ, ZHENG M. 2016. Phylogenetic analysis of VP1 gene sequences of waterfowl parvoviruses from the Mainland of China revealed genetic diversity and recombination. Gene, 578:124-131

WOZ`NIAKOWSKI G, KOZDRUN' W, SAMOREKSALAMONOWICZ E. 2009. Genetic variance of Derzsy's disease strains isolated in Poland. J Mol Genet Med 3(2):210-216

YAKUN LUO AND SHANGJIN CUI. 2015. Goose Parvovirus (Gosling Plague). Molecular Detection of Animal Viral Pathogens, 693-698

ZADORI Z, ERDEI J, NAGY J, KISARY J. 1994 Characteristics of the genome of goose parvovirus. Avian Pathol. ;23(2):359-364.

ZÁDORI Z, STEFANCSIK R, RAUCH T, KISARY J. 1995. Analysis of the complete nucleotide sequences of goose and muscovy duck parvoviruses indicates common ancestral origin with adeno-associated virus 2. Virology; 212 (2):562-573.

ZHANG J, LIU P, WU Y, WANG M, JIA R. 2019. Growth characteristics of the novel goose parvovirus SD15 strain in vitro. BMC Vet Res.; 15: 63.

How to cite this article:

Amani Ali Saleh and Mohamed Hassan Khodier.2020. Preliminary Studies On The Virus Causing Outbreak Of Duckling Short Beak And Dwarfism Syndrome (SBDS) In Egypt Journal of Applied Veterinary Sciences, 5(4): 55 - 60. https://dx.doi.org/10.21608/javs.2020.118004 